\title{
Influence of distance between water distribution and grid fill on water drop size
}

\author{
Pavol Vitkovic ${ }^{1, *}$ \\ ${ }^{1}$ Czech Technical University in Prague, Department of Fluid Dynamics and Thermodynamics, 16607 Prague, Czech Republic
}

\begin{abstract}
The article deals with the experimental study of water drop size measurement below the grid fill. During experiment was changing the distance between the water distribution and grid fill. It's changing the length of impact trajectory on the grid fill. Measurement of the water drop size was located below the first layer of the grid fill.
\end{abstract}

\section{Introduction}

The splash type fill or pack is designed to break the mass of water falling through the cooling tower into a large number of drops [1]. The film fill is more efficient in heat transfer in a smaller volume than the splash fill. But the splash fill has a small surface area exposed to water, it is non-fouling splash fill. It is used in refineries, sugar and steel mills and food processing plants.

The mathematical model of a splash fill is described in [2]. The mathematical model of a rain zone is described in $[3,4]$. All of those models needed a measure a diameter of the water droplets. The small spherical drops can be measured by the IPI method [5]. The splash - grid fill generates non-spherical water droplets. In this case is better to use the laser-induced fluorescence [6].

\section{Experimental facility and setup}

The experimental facility is consisting of a basin, a test section, an extending part, a water pump, a flow meter and a droplet generator. The test section is made from a plexiglass. The dimension of the test section is $0.6 \times 0.6$ $\mathrm{m}$ and a total height of this section is $1 \mathrm{~m}$. The extending part is consisting of several modules with a height of $1 \mathrm{~m}$ and $0.5 \mathrm{~m}$. The modules are made from a galvanized metal sheet. And it can be arbitrarily combined with each other. The water droplets generator is supplied by the water feed pump connected to the water basin below the test section. The water flow rate is measured by the electromagnetic flow meter. The droplets generator was made from plexiglass sheets [6]. It is consisting of a three layers (Fig. 1). The last layer has holes with $1 \mathrm{~mm}$ diameter arranged into the grid $0.01 \times 0.01 \mathrm{~m}$ (Fig 2). The grid of the holes is creating an active zone in the test section. It dimension is $0.2 \times 0.2 \mathrm{~m}$ (Fig. 2). The droplets generator was placed on the top of the experimental facility (Fig. 3). Droplet generator drop size distribution based on volume is on the Fig. 4. It is measured in [6].

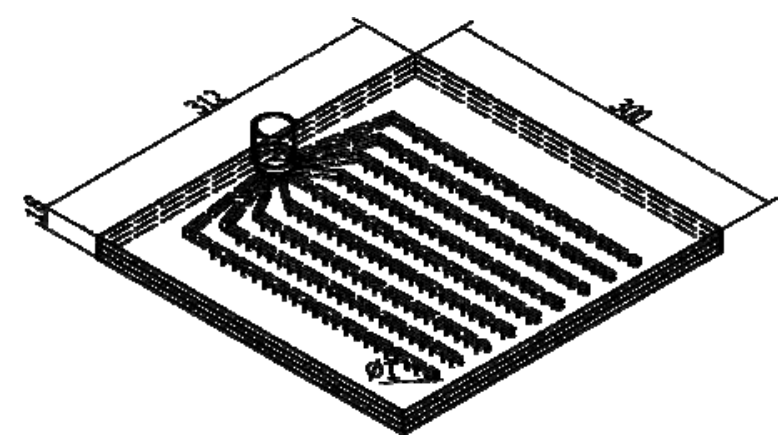

Fig. 1. Droplet generator with the $1 \mathrm{~mm}$ holes.

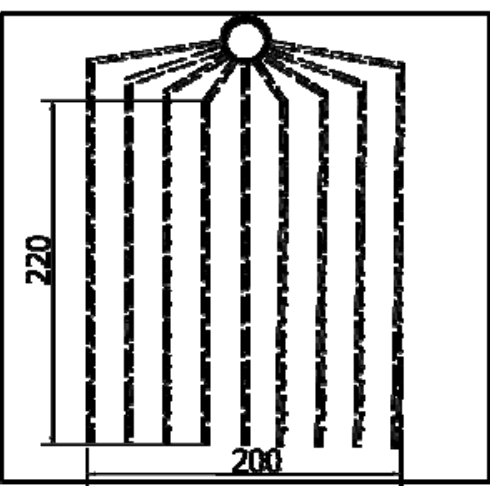

Fig. 2. The active zone of the droplet generator $200 \times 200 \mathrm{~mm}$.

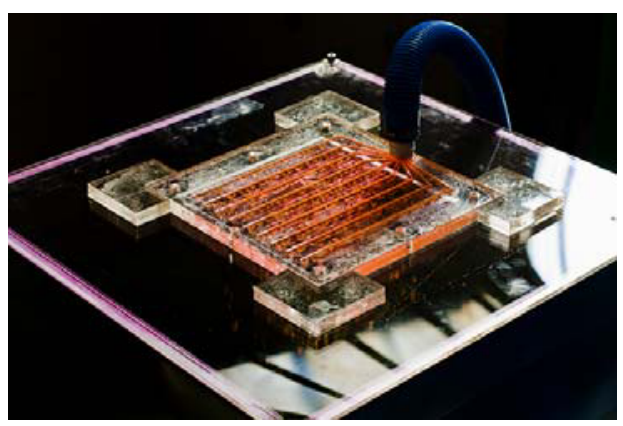

Fig. 3. Droplet generator made from the plexiglass. 


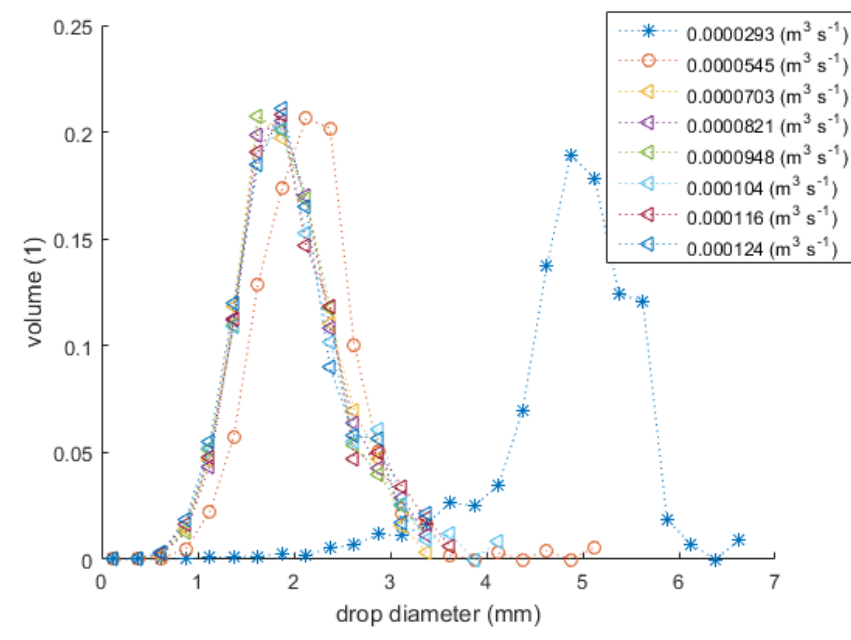

Fig. 4. Droplet generator - drops size distribution based on volume [6].

For all experimental points described below is used the splash (grid) fill with the rhombus shape bars (Fig. 5). The side length of the rhombus is $50 \mathrm{~mm}$ and the thickness of the bar is $5 \mathrm{~mm}$. The layer of grid fill $(0.6 \mathrm{x}$ $0.6 \mathrm{~m}$ ) is placed on the top of the test section (Fig. 6). Above the fill was extending piece. The extending piece has defined the distance between the water drops generator and the grid fill layer. This distance was chosen $0.5 \mathrm{~m}, 1.0 \mathrm{~m}$, and $1.5 \mathrm{~m}$.

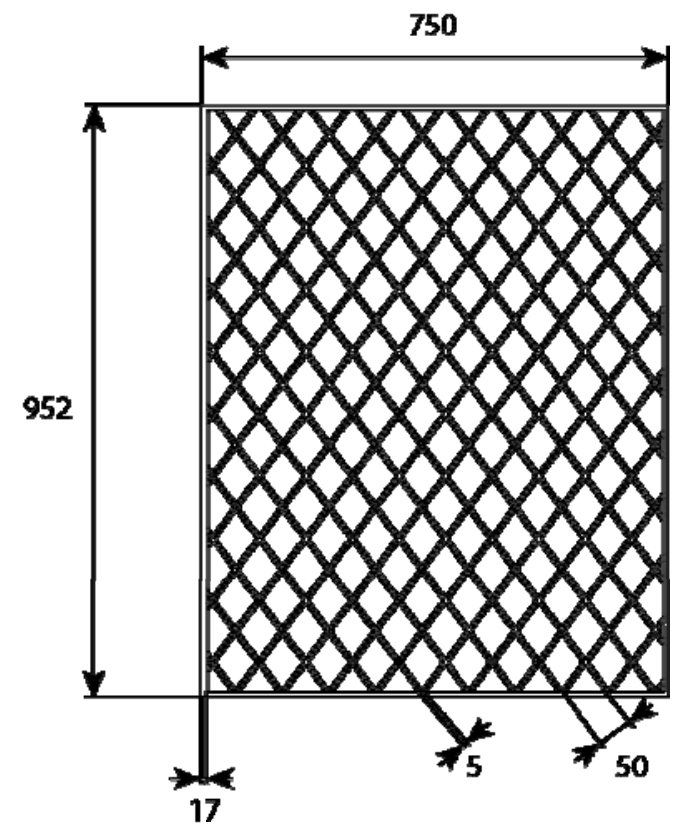

Fig. 5. The splash (grid) fill with the rhombus shape bars.

The test section is located $0.178 \mathrm{~m}$ below the splash (grid) fill. The laser beam is expanded into a sheet using laser optics in the test section (Fig. 7). The Rhodamine G as tracer dye after absorbing the laser light with a wavelength of $523 \mathrm{~mm}$ emitted the light of wavelength between 500 and $700 \mathrm{~nm}$. Excitation light was filtered by a red filter. The images were captured by the camera SONY XCG/H280E with $85 \mathrm{~mm}$ lens. The exposure time was set to $1 / 100 \mathrm{sec}$. The shooting speed was 33 fps. The aperture was set at the $\mathrm{f} / 4$. The Coherent Verdi $\mathrm{G}$ Series semiconductor laser was used. The laser power was set at $1 \mathrm{~W}$.

The water flow rate was chosen from $0.00009 \mathrm{~m}^{3} / \mathrm{s}$ until $0.00047 \mathrm{~m}^{3} / \mathrm{s}$. Totally was 6 measurement points for 3 different distance between the water droplet generator and the splash (grid) fill (Table 1). The first 2 points are covered with an experiment described in [6]. The points from 3 until 6 represent the water flow rate commonly used in the real cooling tower systems.

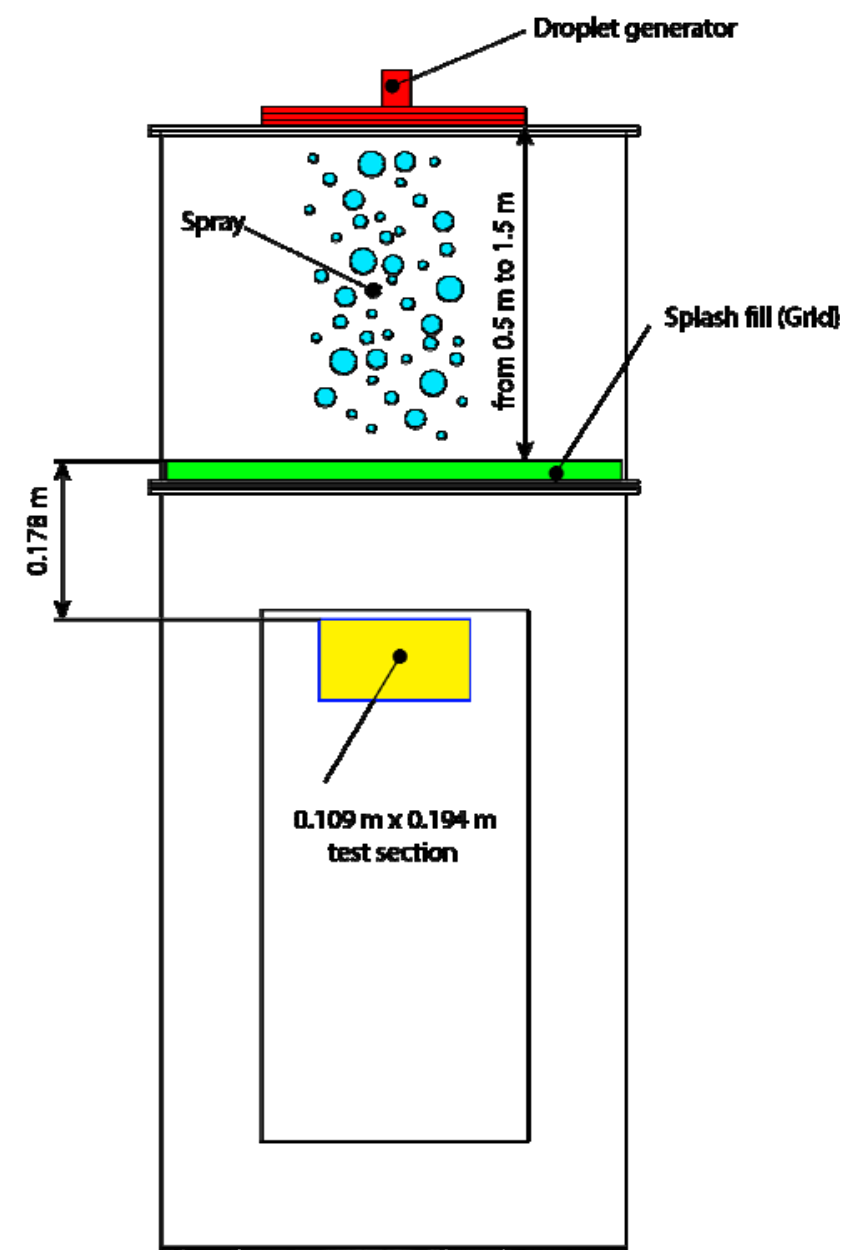

Fig. 6. Experiment setup.

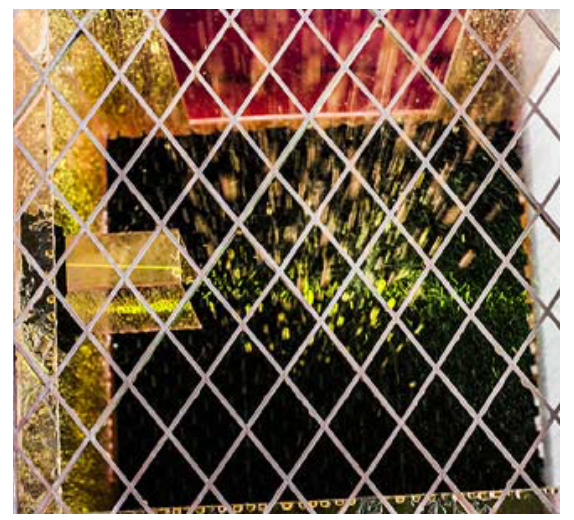

Fig. 7. The laser sheet with the water droplets saturated by Rhodamine G. 
Table 1. Water flow rate for each measurement points and the distance between the drops generator and the splash fill.

\begin{tabular}{|c|c|c|c|}
\hline No. & $\mathrm{H}=0.5 \mathrm{~m}$ & $\mathrm{H}=1.0 \mathrm{~m}$ & $\mathrm{H}=1.5 \mathrm{~m}$ \\
\hline 1 & $0.0000926 \mathrm{~m}^{3} / \mathrm{s}$ & $0.0000912 \mathrm{~m}^{3} / \mathrm{s}$ & $0.0000891 \mathrm{~m}^{3} / \mathrm{s}$ \\
\hline 2 & $0.0001243 \mathrm{~m}^{3} / \mathrm{s}$ & $0.0001224 \mathrm{~m}^{3} / \mathrm{s}$ & $0.0001251 \mathrm{~m}^{3} / \mathrm{s}$ \\
\hline 3 & $0.0001500 \mathrm{~m}^{3} / \mathrm{s}$ & $0.0001524 \mathrm{~m}^{3} / \mathrm{s}$ & $0.0001529 \mathrm{~m}^{3} / \mathrm{s}$ \\
\hline 4 & $0.0002810 \mathrm{~m}^{3} / \mathrm{s}$ & $0.0002808 \mathrm{~m}^{3} / \mathrm{s}$ & $0.0002819 \mathrm{~m}^{3} / \mathrm{s}$ \\
\hline 5 & $0.0003879 \mathrm{~m}^{3} / \mathrm{s}$ & $0.0003885 \mathrm{~m}^{3} / \mathrm{s}$ & $0.0003875 \mathrm{~m}^{3} / \mathrm{s}$ \\
\hline 6 & $0.0004766 \mathrm{~m}^{3} / \mathrm{s}$ & $0.0004730 \mathrm{~m}^{3} / \mathrm{s}$ & $0.0004708 \mathrm{~m}^{3} / \mathrm{s}$ \\
\hline
\end{tabular}

The water flow rate was set up approximately at the same value (Fig. 8) for each distance between the water droplet generator and the fill layer.

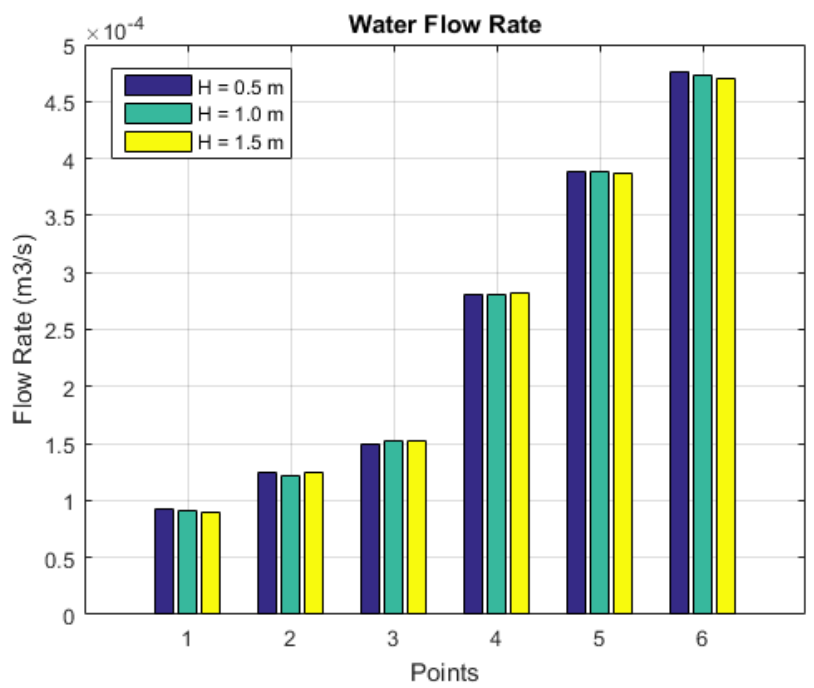

Fig. 8. Water flow rate during the experiment

\section{Experimental results}

The signal from the fluorescent light is converted to the white blobs on a black background. From the blob area is calculated an equivalent spherical drop diameter. The water drop size distribution based on volume are at following figures (Fig. 9 - Fig. 14) for different water flow rates and different between the droplet generator and grid fill. Each histogram represents the amount of water for individual diameters of the water drops.

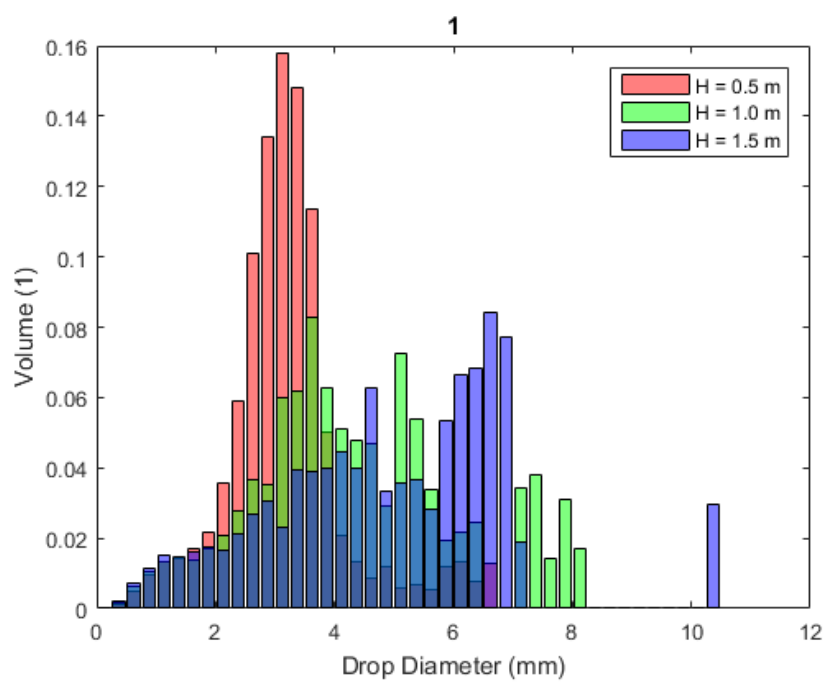

Fig. 9. Drop size histogram based on volume for the mean water flow rate $0.0000910 \mathrm{~m}^{3} / \mathrm{s}$

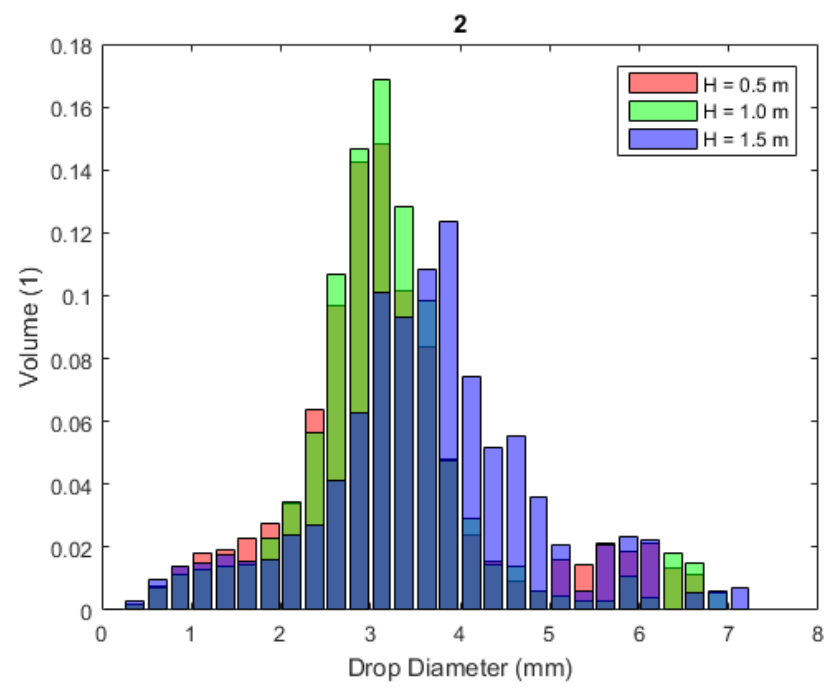

Fig. 10. Drop size histogram based on volume for the mean water flow rate $0.0001239 \mathrm{~m}^{3} / \mathrm{s}$

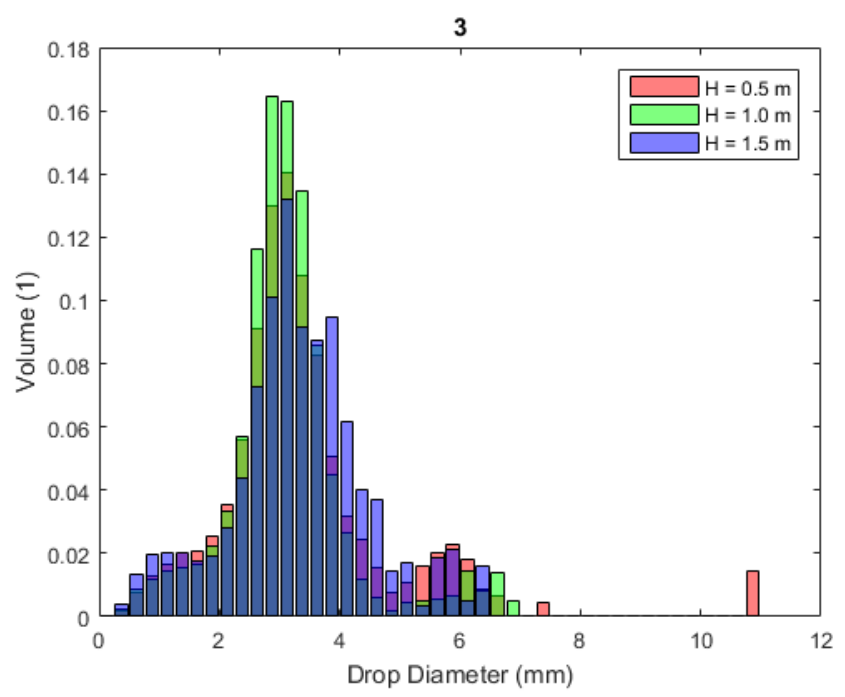

Fig. 11. Drop size histogram based on volume for the mean water flow rate $0.0001517 \mathrm{~m}^{3} / \mathrm{s}$ 


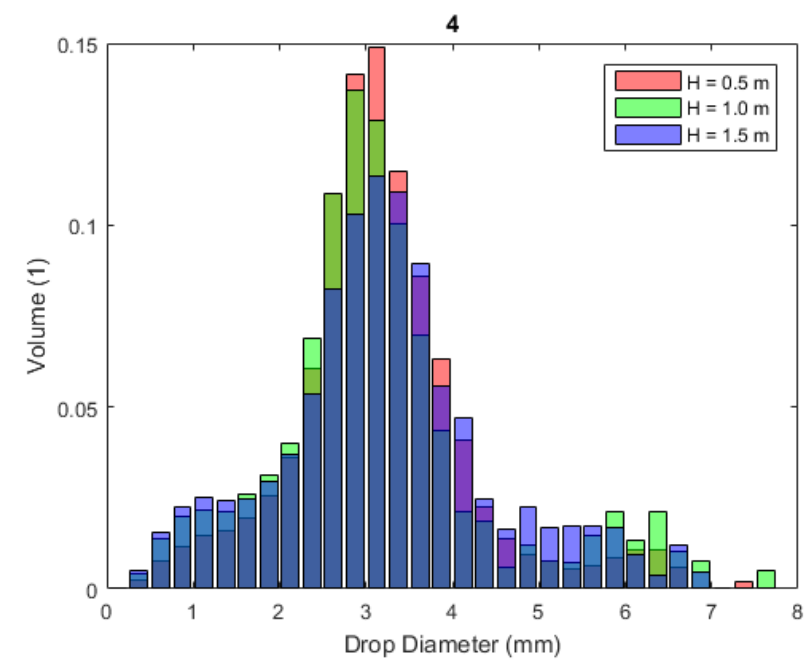

Fig. 12. Drop size histogram based on volume for the mean water flow rate $0.0002812 \mathrm{~m}^{3} / \mathrm{s}$

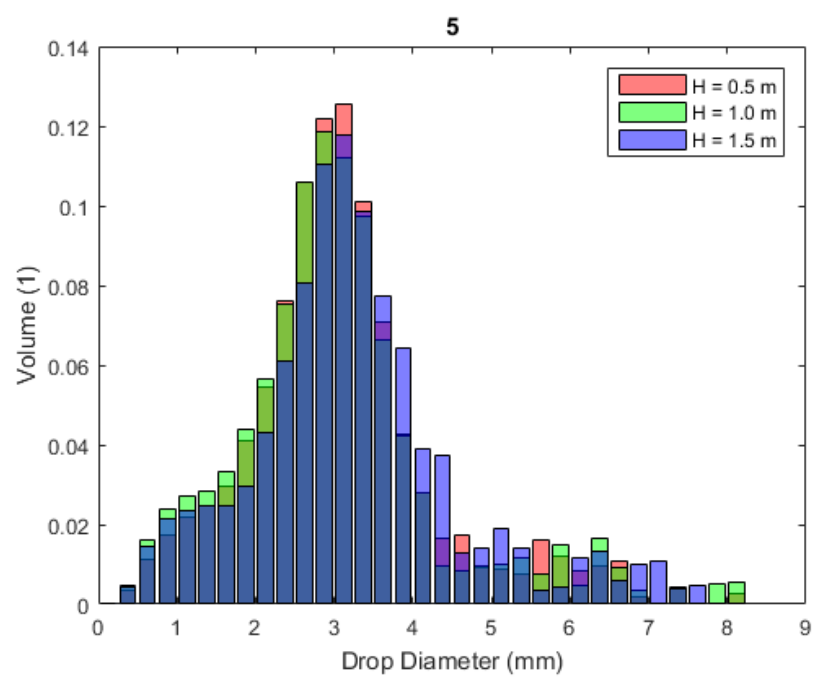

Fig. 13. Drop size histogram based on volume for the mean water flow rate $0.0003880 \mathrm{~m}^{3} / \mathrm{s}$

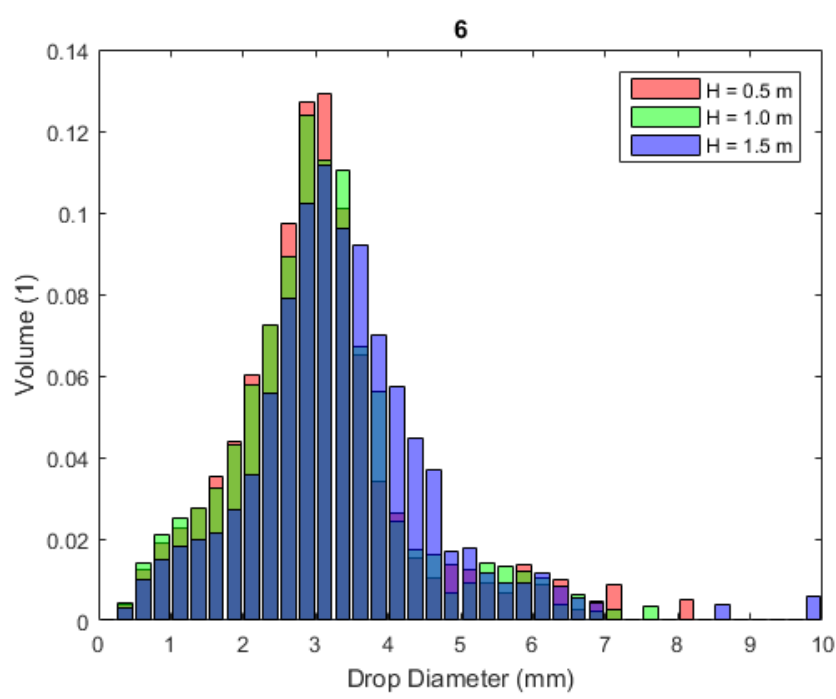

Fig. 14. Drop size histogram based on volume for the mean water flow rate $0.0004735 \mathrm{~m}^{3} / \mathrm{s}$

\section{Conclusion}

The experimental data was obtained for splash (grid) fill with rhombus shaped bars. They have chosen 3 distances between the water droplet generator and the fill layer. For study was used 1 layer of the splash fill. The splash (grid) fill with the rhombus shape bar generate the biggest water droplet like they come at the fill. It is confirming the experimental results in [6]. The water droplet generator is creating a mean droplet with diameter $2 \mathrm{~mm}$. The splash fill is creating a mean droplet with a diameter of $3 \mathrm{~mm}$ and more. The study shows that the influence of the distance between the spray device (in this case the water droplet generator with $1 \mathrm{~mm}$ holes) is very weak. The histograms on Fig. 11 till Fig. 14 are covered for each distance between the droplet generator and the fill layer. It means that no matter the chosen distance. However, the influence is discovered in Fig. 9 and significantly less on Fig. 10 at the lowest water flow rates. This water flow rates are not commonly used in the real cooling tower.

\section{Acknowledgments}

The author acknowledges the support received from Advanced technologies for heat and electricity production TE01020036, Centre for research of multiphase flow and thermodynamics processes in renewable sources and energetics - NEW ENERGY supported by the European Union (CZ.2.16/3.1.00/22130) and Centre of 3D volumetric velocimetry - COLA supported by the European Union (CZ.2.16/3.1.00/21569).

\section{References}

1. D.G Kröger, Air-Cooled Heat Exchangers and Cooling Tower, (2004)

2. A. A. Dreyer, P. J. Erens, J. Heat Mass Transfer, 39, 109-123, (1996)

3. T. Hyhlík, Engineering Mechanics, 21, 240-243, (2014)

4. T. Hyhlík, ICCT 2014 International Conference, 219-226, (2014)

5. J. Stodůlka, R. Vitkovicova, EPJ Web of Conferences, 114, 02111, (2016)

6. P. Vitkovic, EPJ Web of Conferences, 114, 02137 , (2016) 